\title{
Evidence that methylphenidate Treatment Evokes Anxiety-Like Behavior Through Glucose Hypometabolism and Disruption of the Orbitofrontal Cortex Metabolic Networks
}

\section{Felipe Schmitz ( $\square$ felipe.schmitz@ufrgs.br)}

Federal University of Rio Grande do Sul: Universidade Federal do Rio Grande do Sul

https://orcid.org/0000-0002-9746-0286

Josiane Silva Silveira

UFRGS: Universidade Federal do Rio Grande do Sul

Gianina T Venturin

PUCRS: Pontificia Universidade Catolica do Rio Grande do Sul

\section{Samuel Greggio}

PUCRS: Pontificia Universidade Catolica do Rio Grande do Sul

\section{Guilherme Peixoto}

UFRGS: Universidade Federal do Rio Grande do Sul

\section{Eduardo Zimmer}

UFRGS: Universidade Federal do Rio Grande do Sul

\section{Jaderson Costa}

PUCRS: Pontificia Universidade Catolica do Rio Grande do Sul

\section{Angela Wyse}

UFRGS: Universidade Federal do Rio Grande do Sul

\section{Research Article}

Keywords: psychostimulant, attention-deficit/hyperactivity disorder, molecular imaging, brain activity, orbitofrontal cortex, anxiety-like behavior

Posted Date: February 19th, 2021

DOl: https://doi.org/10.21203/rs.3.rs-217037/v1

License: (c) (i) This work is licensed under a Creative Commons Attribution 4.0 International License. Read Full License 
Version of Record: A version of this preprint was published at Neurotoxicity Research on November 19th, 2021. See the published version at https://doi.org/10.1007/s12640-021-00444-9. 


\section{Abstract}

Methylphenidate (MPH) has been widely misused by children and adolescents who do not meet all diagnostic criteria for attention-deficit/hyperactivity disorder without a consensus about the consequences. Here, we evaluate the effect of MPH treatment on glucose metabolism and metabolic network in the rat brain, as well as on performance in behavioral tests. Wistar male rats received intraperitoneal injections of MPH $(2.0 \mathrm{mg} / \mathrm{kg})$ or an equivalent volume of $0.9 \%$ saline solution (controls), once a day, from the 15th to the 44th day of age. Fluorodeoxyglucose-18 was used to investigate the cerebral metabolism, and a cross-correlation matrix was used to examine the brain metabolic network in $\mathrm{MPH}$-treated rats using micro-positron emission tomography imaging. Performance in the light-dark transition box, eating-related depression, and sucrose preference tests were also evaluated. While MPH provoked glucose hypermetabolism in the auditory, parietal, retrosplenial, somatosensory, and visual cortices; hypometabolism was identified in the left orbitofrontal cortex. MPH-treated rats show a brain metabolic network more efficient and connected, but careful analyzes reveal that the MPH interrupts the connection of the orbitofrontal cortex with other brain areas. Anxiety-like behavior was also observed in $\mathrm{MPH}$-treated rats. This study shows that glucose metabolism evaluated by microPET in the brain can be affected by MPH in different ways according to the region of the brain studied. It may be related, at least in part, to a rewiring in brain the metabolic network and behavioral changes observed, representing an important step in exploring the mechanisms and consequences of MPH treatment.

\section{Introduction}

Methylphenidate (MPH), a central nervous system (CNS) stimulant in use for approximately 70 years, is the drug of choice for pharmacological treatment of attention-deficit/hyperactivity disorder (ADHD) [1]. ADHD is one of the most common neurodevelopmental disorders of childhood characterized by inattention and/or hyperactive-impulsive behaviors [2-4]. Most recently, researchers have also been quite concerned about the increased incidence of MPH misuse among individuals not meeting the criteria for ADHD, as a "cognitive enhancer" and as an alternative to other psychostimulants for recreational use [5$7]$, as well as in preschool children with $2-4$ years of age $[8,9]$.

The MPH neuropharmacological profile is similar to amphetamine and cocaine [10], but the complete mechanisms of MPH are still unknown [11, 12]. Functionally, MPH has been proposed as a high-affinity inhibitor of dopamine (DA) and norepinephrine (NE) transporters, blocking the inward transport of DA and NE [13-15]. DA transporter (DAT) plays an essential role in terminating DA signaling, since DA levels are primarily regulated by removing extracellular DA and recycling it back to the neuron [16].

DA is a major modulatory neurotransmitter that controls a number of important physiological functions, such as brain activity and metabolism [17], including modulation of grey matter metabolism and neurometabolic coupling in both healthy human brain and psychopathology [18]. Several lines of evidence point to the alteration in brain metabolic homeostasis in MPH mechanisms [19-22]. Furthermore, MPH is known to elevate neuronal activity, as evident from its ability to increase the 
transcription of several activity dependent genes, together with their corresponding proteins [23-25], and it is likely that this effect is dependent on a local elevated level of ATP metabolism. In this context, we showed recently that rats subjected to chronic exposure to MPH had reduced levels of ATP in the hippocampus [26]. Yet, as far as we know, the effects of early chronic administration with MPH on glucose metabolism in different brain regions of rats remain largely unknown. However, since glucose is the main energy source for the brain, it is possible that the effects of MPH on energy metabolism are modulated by changes in glucose consumption in the brain.

Glucose metabolism changes have been correlated with anxiety-like and depression-like behaviors [27]. In addition, excessive levels of DA and NE are positively related to the state of anxiety in organisms [28-31]. Corroborating this, many anxiety-like and depression-like behaviors are often induced by drugs that disturb neurotransmitter systems [32-35], including dopaminergic/norepinephrinergic system [36]. However, the effects on plus-maze observed following chronic MPH treatment have yielded mixed results; increases [37], decreases [38], and no change in anxious behaviors [39]. Vendruscolo et al. [40] showed that chronic treatment with MPH ( $2 \mathrm{mg} / \mathrm{kg}$ intraperitoneally; twice daily for 16 days) elicited anxious-like behavior in the open-field but not in the elevated plus-maze.

The use and misuse of MPH are increasing, particularly during childhood and adolescence, periods characterized by rapid development of CNS and intense cellular proliferation and growth [9]. This has raised concerns regarding its long-term side effects and potential toxicity to the CNS [22, 41-44]. Glucose is the main energy source for the brain; however, there is little information about the effects of MPH on glucose brain metabolism. In this regard, Zhang and colleagues $[45,46]$ have demonstrated that microPET imaging is a very useful tool capable of distinguishing differences in retention of fluorodeoxyglucose-18 $\left({ }^{18} \mathrm{~F}-\mathrm{FDG}\right)$ in the brains of rodent and the nonhuman primate treated chronically with MPH exploring the effects of this psychostimulant on aspects of brain function.

Taking all this into account, we investigated brain glucose metabolism and the metabolic network in chronically MPH-treated rats, using ${ }^{18} \mathrm{~F}-\mathrm{FDG}$ and micro positron emission tomography (microPET) as a noninvasive imaging tool. MPH effects on light-dark transition box, eating-related depression, and sucrose preference tests were also evaluated. We hypothesized that changes in brain glucose metabolism, metabolic network architecture and depressive-and anxiety-like behaviors may be involved in the MPH effects since their regulating may be modulated by dopaminergic neurotransmission, MPH's main target.

\section{Experimental Procedures}

\section{Animals and reagents}

Rats were obtained from the Central Animal House of the Department of Biochemistry of the University Federal of Rio Grande do Sul, Porto Alegre, Brazil. Litters were culled to eight pups on postnatal day (PD) 3 (day of parturition = PD 0) and were kept with the dam until weaning on PD 21. After weaning, the rats 
were re-housed in boxes containing up to four male rats. Animals were maintained on a 12-12 light-dark cycle at a constant temperature of $22 \pm 1^{\circ} \mathrm{C}$, with free access to water and commercial protein chow. Sample sizes were determined as 10 and 17 animals per group for ${ }^{18} \mathrm{~F}$-FDG microPET study and behavioral testing, respectively, based on standard deviation values of previous studies, with power estimation of 0.80 and alpha $=0.05$. A total of 40 male Wistar rats were used.

All chemicals were obtained from Sigma Chemical Co., St. Louis, MO, USA.

\section{Chronic early treatment with methylphenidate}

Beginning on PD 15, rats were weighed and injected daily intraperitoneally with saline solution $(0.9 \%)$ or $\mathrm{MPH}(2.0 \mathrm{mg} / \mathrm{kg})$, for thirty consecutive days, as previously described in reports of our research group [26, 47-52]. Briefly, MPH was dissolved in $0.9 \%$ saline solution and injected at a volume of $1 \mathrm{~mL} / 100 \mathrm{~g}$ of body weight. Control group received equivalent volume of saline solution. This dose and route of administration were selected because they mimic the therapeutic doses in terms of magnitude of neurochemical and behavioral effects [53]. MPH administrations started at 15 days of life because this period is characterized by intense synaptogenesis, myelination and gliogenesis, comparable to early childhood in humans [54]. Treatment lasted for thirty days because it has been shown that this period mimics chronic use in humans [55]. Twenty-four hours after the last administration of MPH, the rats were subjected to the MicroPET scanning of ${ }^{18} \mathrm{~F}-\mathrm{FDG}$ uptake in the brain. The next day, we started the functional behavioral assessments. Then, the animals were beheaded and the brains were removed for parallel studies. We did not observe any significant difference in weight gain between the groups during the treatment $(p>0.05)$, as showed in Supplementary Fig. 1. The study design is outlined in Fig. 1.

\section{${ }^{18} \mathrm{~F}-\mathrm{FDG}$ micro-PET brain scan}

Twenty-four hours after the last saline and MPH injection, the animals from each group (control $n=10$ and $\mathrm{MPH} n=10$ ) were individually anesthetized using a mixture of isoflurane and medical oxygen (3-4\% induction dose), and injected with $0.4 \mathrm{~mL}{ }^{18} \mathrm{~F}-\mathrm{FDG}$ (sham $=38.05 \pm 1.06 \mathrm{MBq}$ and $\mathrm{MPH}=37.56 \pm 1.08$ $\mathrm{MBq}$ ) in the tail vein, after overnight fasting. Then, each rat was returned to its home cage for a $40 \mathrm{~min}$ period of conscious (awake) in vivo metabolism of ${ }^{18} \mathrm{~F}-\mathrm{FDG}$. After the uptake period, each rat was placed in a head-first prone position and scanned with the Triumph ${ }^{\text {TM }}$ micro-PET (LabPET-4, TriFoil Imaging, Northridge, CA, USA) under inhalational anesthesia (2-3\% maintenance dose). Throughout these procedures, the animals were kept on a pad heated at $37^{\circ} \mathrm{C}$. For radiotracer readings, $10 \mathrm{~min}$ list mode static acquisitions were acquired with the field of view $(\mathrm{FOV} ; 3.75 \mathrm{~cm})$ centered on each rat's head [56, 57]. All data were reconstructed using the maximum likelihood estimation method (MLEM-3D) algorithm with 20 iterations. Each microPET image was reconstructed with a voxel size of $0.2 \times 0.2 \times 0.2 \mathrm{~mm}$ and spatially normalized into an ${ }^{18} \mathrm{~F}-\mathrm{FDG}$ template using brain normalization in PMOD v3.8 and the Fuse It Tool (PFUSEIT) (PMOD Technologies, Zurich, Switzerland). An MRI rat brain volume of interest (VOI) template was used to overlay the normalized images previously coregistered to the microPET image database. Activity values were normalized for the injected dose and the animal body weight, and were 
therefore expressed in standard uptake values (SUVS). The SUV was calculated for the whole brain and each individual region. In order to correct for weight variations, we calculated the SUV ratio (SUVr) of each individual brain region by dividing the SUV value of the region by the whole brain SUV [57-59]. Mean SUVs of 14 brain regions were extracted using a predefined VOI template. For analysis at the voxel level, MINC tools (www.bic.mni.mcgill.ca/ServicesSoftware) were used for image processing and analysis.

\section{Metabolic networks}

Metabolic brain networks (MBNs), derived from ${ }^{18}$ F-FDG SUV regional data, were constructed by computing Pearson's correlation coefficient based on 1,000 bootstrap samples. The correlation maps were built using the VOIs. The graph theoretical measures, global efficiency, density, assortativity coefficient and average clustering coefficient were computed using the $10 \mathrm{MBNs}$ most similar to the mean MBN of each group. Networks computed this way were corrected for multiple comparisons using false discovery rate (FDR) at $p<0.001$ [60]. In short, global efficiency is a measure of how effectively the network interchange information between its nodes; density quantifies the overall number of edges of a network; assortativity coefficient measures the network resilience; and the clustering coefficient corresponds to the portion of the node's neighbors that are also neighbors of each other [61].

\section{Behavioral assessment}

Behavioral evaluation of thirty-four rats (control $n=17$ and MPH $n=17$ ) was carried out $24 \mathrm{~h}$ after the microPET assessment of ${ }^{18}$ F-FDG uptake in brain, and the tests were performed on the 7 following days. The behavioral performance of the animals was evaluated on the following tests: light-dark transition, eating-related depression, and sucrose preference.

\section{Light-dark transition test}

A light-dark transition test was conducted as previously described by Takao and Miyakawa [62]. The apparatus used for the light-dark transition test comprised a cage $(21 X 42 X 25 \mathrm{~cm})$ divided into two sections of equal size by a partition with a door (Ohara \& Co., Tokyo). One chamber was brightly illuminated (390 lux), whereas the other chamber was dark (2 lux). Rats were placed into the dark side and allowed to move freely between the two chambers with the door open for $10 \mathrm{~min}$. The total number of transitions, and time spent in each chamber were evaluated.

\section{Eating-related depression test}

This test examines the levels of depression and motivation to eat after food deprivation [63]. In this test, all food was removed from the animal cages for 24 hours. After, a few food pellets were placed on a piece of filter paper positioned at one of the 4 corners of the home cage, and each animal was placed in a corner opposite to the food, free to explore for 5 minutes. To exclude odor-related issues, the food pellets were changed for each rat. The latency of the first bite was measured.

\section{Sucrose preference test}


The sucrose preference test was performed as described by Upadhya et al. [63]. Briefly, on the first day, the animals were trained to adapt to sucrose solution for 24 hours. Animals were housed in individual cages with free access to 2 identical bottles, each containing $100 \mathrm{~mL}$ of $1 \%$ sucrose and food provided ad libitum. On the second day, the animals had free access to 2 bottles, one containing $100 \mathrm{~mL}$ of $1 \%$ sucrose and the other containing $100 \mathrm{~mL}$ of water (food was provided ad libitum). On the third day, the animals were deprived of water and food for 22 hours. On the last day, the animals had free access to 2 bottles, one containing $100 \mathrm{~mL}$ of $1 \%$ sucrose and the other containing $100 \mathrm{~mL}$ of water. After 2 hours of testing, water and sucrose consumption were measured.

\section{Statistical analyses}

The analyses were performed using the Statistical Package for the Social Sciences (SPSS) software, in a PC-compatible computer. Student's $t$ test was used to evaluate all different parameters after checking data normal distribution with Shapiro-Wilk test. Results are expressed as means \pm standard deviation or standard error mean, and differences were considered statistically significant when $p<0.05$. Networks were corrected for multiple comparisons using FDR at $p<0.001$. GraphPad Prism 6 was used for statistical analysis. In all cases, litter effects were controlled by assigning not more than two subjects from a litter to a particular group.

\section{Results}

\section{MicroPET approaches}

\section{MPH disrupts brain glucose metabolism homeostasis}

Initially, we evaluated the effect of chronic MPH treatment on the brain glucose metabolism. As we can see in Fig. 2A, MPH did not alter the whole-brain ${ }^{18} \mathrm{~F}-\mathrm{FDG}$ uptake $(p>0.05)$ when compared to control group. Figure 2B shows the representative microPET images of cerebral ${ }^{18} \mathrm{~F}-\mathrm{FDG}$ uptake for control and MPH groups: axial (top), sagittal (middle) and coronal (bottom) sections.

To closely observe the effect of MPH treatment on glucose metabolism, we evaluated the ${ }^{18} \mathrm{~F}$-FDG uptake in each brain region. MPH provoked glucose hypermetabolism in the auditory $(p<0.01)$, parietal $(p<$ $0.05)$, retrosplenial $(p<0.05)$, somatosensory $(p<0.05)$ and visual $(p<0.01)$ cortices. ${ }^{18} F-F D G$ uptake was not affected by MPH in the orbitofrontal, frontal association, medial prefrontal and motor cortices $(p>$ 0.05) (Table 1). 
Table 1

Effect of chronic treatment with MPH on glucose metabolism in brain $\left({ }^{18} \mathrm{~F}-\mathrm{FDG}\right.$ SUVr) from juvenile rats

\begin{tabular}{|c|c|c|c|}
\hline Brain region & Control & MPH & $P$ value \\
\hline Auditory cortex & $0.0292 \pm 0.00054$ & $0.0304 \pm 0.00083$ & $0.002^{\star \star}$ \\
\hline Parietal cortex & $0.0312 \pm 0.00128$ & $0.0325 \pm 0.00080$ & $0.018^{\star}$ \\
\hline Restroplenial cortex & $0.0319 \pm 0.00121$ & $0.0331 \pm 0.00127$ & $0.046^{\star}$ \\
\hline Somatosensory cortex & $0.0337 \pm 0.00097$ & $0.0346 \pm 0.00055$ & $0.014^{*}$ \\
\hline Visual cortex & $0.0300 \pm 0.00097$ & $0.0316 \pm 0.00094$ & $0.002^{\star *}$ \\
\hline Orbitofrontal cortex & $0.0363 \pm 0.00130$ & $0.0351 \pm 0.00169$ & 0.072 \\
\hline Frontal association cortex & $0.0283 \pm 0.00197$ & $0.0276 \pm 0.00192$ & 0.463 \\
\hline Medial prefrontal cortex & $0.0410 \pm 0.00132$ & $0.0407 \pm 0.00085$ & 0.518 \\
\hline Motor cortex & $0.0334 \pm 0.00159$ & $0.0340 \pm 0.00088$ & 0.309 \\
\hline Hippocampus & $0.0628 \pm 0.00132$ & $0.0621 \pm 0.00095$ & 0.169 \\
\hline Hippocampus anterodorsal & $0.0340 \pm 0.00086$ & $0.0340 \pm 0.00059$ & 0.820 \\
\hline Hippocampus posterior & $0.0288 \pm 0.00086$ & $0.0282 \pm 0.00051$ & 0.054 \\
\hline
\end{tabular}

${ }^{18} \mathrm{~F}-\mathrm{FDG}$ uptake in the left and right side of those brain regions were also evaluated. MPH provoked glucose hypermetabolism in the auditory cortex [right $(p<0.05)$ and left $(p<0.01)$ ], parietal cortex [left ( $<0.01)$ ], retrosplenial cortex [left $(p<0.05)$ ], somatosensory cortex [left $(p<0.01)$ ], and visual cortex [right $(p<0.05)$ and left $(p<0.01)]$, as showed in Fig. 3A, B, C, D and E, respectively. On the other hand, glucose hypometabolism was identified in the left orbitofrontal cortex $(p<0.05)$, as we can see in Fig. 3F. Figure $3 \mathrm{G}, \mathrm{H}$ and $\mathrm{I}$, shows that ${ }^{18} \mathrm{~F}-\mathrm{FDG}$ uptake was not affected by MPH treatment in the frontal association, medial prefrontal and motor $(p>0.05)$ cortices, when compared to control group.

We also evaluated the ${ }^{18} \mathrm{~F}-\mathrm{FDG}$ uptake in hippocampus, an important brain region associated with MPH effects. ${ }^{18} \mathrm{~F}-\mathrm{FDG}$ uptake in total hippocampus, anterodorsal and posterior hippocampus were not affected by MPH treatment $(p>0.05)$ (also showed in Table 1). We also did not observe any lateralized effects in hippocampus ( $p>0.05$ ) (Fig. 4). Although it is not statically significant, left hippocampus posterior of MPH-treated rats presented a tendency to show a decrease in glucose metabolism $(p=0.054)$ (Fig. 4C).

Further, ${ }^{18} \mathrm{~F}-\mathrm{FDG}$ uptake was not affected by MPH treatment in other brain regions, namely: accumbens, amigdala, striatum, cingulate cortex, entorhinal cortex, cerebellum, insular cortex, hypothalamus, 
olfactory, colliculus superior, midbrain, ventral tegmental area, colliculus inferior, cortex and thalamus, as showed in Table 2.

Table 2

Effect of chronic treatment with MPH on glucose metabolism in brain $\left({ }^{18} \mathrm{~F}\right.$-FDG SUVr) from juvenile rats

\begin{tabular}{|llll|}
\hline Brain region & Control & MPH & P value \\
\hline Accumbens & $0.0345 \pm 0.00075$ & $0.0339 \pm 0.00114$ & 0.187 \\
\hline Amigdala & $0.0243 \pm 0.00069$ & $0.0240 \pm 0.00089$ & 0.304 \\
\hline Striatum & $0.0384 \pm 0.00074$ & $0.0387 \pm 0.00076$ & 0.417 \\
\hline Cingulate cortex & $0.0402 \pm 0.00118$ & $0.0401 \pm 0.00116$ & 0.820 \\
\hline Entorhinal cortex & $0.0236 \pm 0.00102$ & $0.0233 \pm 0.00108$ & 0.453 \\
\hline Cerebellum & $0.0551 \pm 0.00240$ & $0.0541 \pm 0.00186$ & 0.309 \\
\hline Insular cortex & $0.0301 \pm 0.00090$ & $0.0304 \pm 0.00096$ & 0.451 \\
\hline Hypothalamus & $0.0266 \pm 0.00083$ & $0.0264 \pm 0.00086$ & 0.739 \\
\hline Olfactory & $0.0296 \pm 0.00167$ & $0.0287 \pm 0.00172$ & 0.271 \\
\hline Colliculus superior & $0.0367 \pm 0.00117$ & $0.0369 \pm 0.00129$ & 0.726 \\
\hline Midbrain & $0.0328 \pm 0.00070$ & $0.0331 \pm 0.00078$ & 0.499 \\
\hline Ventral tegmental area & $0.0282 \pm 0.00066$ & $0.0280 \pm 0.00103$ & 0.631 \\
\hline Colliculus inferior & $0.0372 \pm 0.00118$ & $0.0373 \pm 0.00137$ & 0.927 \\
\hline Thalamus & $0.0359 \pm 0.00130$ & $0.0362 \pm 0.00053$ & 0.505 \\
\hline Cortex & $0.3890 \pm 0.00802$ & $0.3933 \pm 0.00682$ & 0.217 \\
\hline $\begin{array}{l}\text { Results are expressed as mean } \pm \text { standard deviation for } 10 \text { animals in each group. MPH, } \\
\text { methylphenidate; }{ }^{18} \mathrm{~F}-\mathrm{FDG}, \text { fluorodeoxyglucose-18; SUVr, standardized uptake value ratio }\end{array}$ \\
\hline
\end{tabular}

In Table S1, we also show the right and left side results found for each one of these structures, as well as the ${ }^{18} \mathrm{~F}-\mathrm{FDG}$ uptake measured in the pituitary, cerebellum blood, central canal, pons, septum, and medulla.

MPH-treated rats show a more efficient and connected brain metabolic network among most regions evaluated, but not in the left orbitofrontal cortex

Metabolic networks analyses across previously delineated VOls were performed to identify brain reorganization patterns after MPH treatment. Compared to control, MPH induced metabolic hypersynchronicity, promoting a higher number of connections in several brain regions, including the right entorhinal cortex, left and right insular cortex and specially the cerebellum. In contrast, MPH reduced the number of metabolic connection patterns in the orbitofrontal cortex $(p<0.001$, FDR corrected, Fig. 5A-D). 
Global graph theoretical measures demonstrated a consistent reorganization in the brain metabolic network indexed by higher global efficiency $(p<0.0001$, Fig. 5E), assortativity coefficient $(p<0.0001$, Fig. 5F), density ( $p<0.0001$, Fig. $5 G)$, and average clustering coefficient $(p=0.0089$, Fig. $5 H)$ in $\mathrm{MPH}-$ treated rats.

\section{Behavioral approaches}

\section{MPH induces anxiety-like behavior in rat}

In the light-dark transition test, a tool to analyze anxiety-like behavior, we found that MPH-group spends less time in light box $(p<0.05)$, when compared to the control group (Fig. 6A). Total light-dark transitions were not affected by MPH treatment (Fig. 6B). Less time spent on the light side suggests that animals undergoing early chronic treatment with MPH exhibit anxious behavior when compared to the group that received saline solution.

\section{MPH did not induces depressive-like behavior in rat, but increases the positive reinforcement}

In the eating-related depression test, a tool to examine the levels of depression and motivation to eat after food deprivation, we did not identify differences between MPH and control ( $p>0.05)$ (Figure S2).

In the sucrose preference test, a tool to analyze anhedonia, a depressive-like behavior, control and MPHtreated rats showed a bigger consumption of sucrose solution ( $p<0.05$ and $p<0.001$, respectively) (Fig. 6C,D). Differently than we imagined, Fig. 6E shows that MPH increased the preference for sucrose in relation to the control group $(p<0.05)$. This result suggests that MPH increases the positive reinforcement caused by sucrose. We did not identify differences between groups about total volume consumption $(p>0.05)$ (Fig. 6F).

\section{Discussion}

The current study was proposed to examine the effects of early chronic treatment with MPH on glucose metabolism and the metabolic network patterns in juvenile rat brain using microPET. We also attempted to determine whether the MPH treatment affects the performance in the light-dark transition box, eatingrelated depression, and sucrose preference tests. First, we showed that MPH caused changes in glucose uptake in several regions of the brain, with more pronounced effects on the left side. In this context, the left orbitofrontal cortex was the only structure that showed a decrease in glucose metabolism. Then, we also observed that rats treated with MPH have a more efficient and connected brain metabolic network between most of the evaluated regions, but the orbitofrontal cortex showed a loss of its connectivity with other areas of the brain. Finally, the results of behavioral assessments suggest that rats treated with MPH developed behavior similar to anxiety and also showed a greater sensitivity to the positive reinforcement promoted by sucrose when compared to the control group. As far as we know, the effects on glucose metabolism in different brain regions of juvenile rats submitted to early chronic treatment with a clinically 
relevant dose of MPH have not been extensively investigated to date. Also, new is the possible relationship among changes in brain glucose metabolism with the brain metabolic network and the behavioral changes shown here.

It has been previously demonstrated that MPH increases mitochondrial respiratory chain enzymes [20], leads to abnormalities on Krebs cycle enzymes in the brain of young and adult rats [21,22], induces changes in glucose uptake, which were age-and dose-related, in brain regions that are associated with ADHD [64], and also that treatments with MPH increased the activity of creatine kinase, an important enzyme in cell homeostasis, in the brains of young and adult rats [22]. Based on these studies, although the MPH's precise neurochemical mechanism of action is under debate, it is reasonable to hypothesize that cerebral glucose metabolism changes are associated with MPH treatment, since there is no doubt about MPH's ability to affect the dopaminergic system $[13,65]$, which has been strongly related to the glucose supply and uptake by brain $[66,67]$. Corroborating our hypothesis, we observed a hypermetabolism of glucose in the auditory and visual cortices on both sides, with a more pronounced effect on the left side after chronic MPH administration. We also observed a hypermetabolism of glucose on the left side of the parietal, retrosplenial and somatosensory cortices, further suggesting that treatment with MPH promotes greater dopaminergic activity, especially on the left side. According to these findings, amphetamine, a psychostimulant that acts by increasing available DA, improved glucose uptake in the rat striatum, frontal cortex and hippocampus [68]. 7-OH-DPAT, quinpirole and SKF 38393, which are dopamine receptor agonists, have been shown to change glucose uptake in the brain $[66,67]$. Kim et al. [69] in a PET study demonstrated that MPH administrated for 6 weeks ( $0.3 \mathrm{mg} / \mathrm{kg}$ per day) increased cerebral glucose metabolism in patients with impaired consciousness after traumatic brain injury. So, although it is not possible to establish the precise mechanism behind the MPH induced elevation of glucose metabolism in this study, it is likely that this effect is related to the known blockade of DAT by MPH, which increases synaptic DA levels and hence DA receptor stimulation.

The left orbitofrontal cortex was the only brain region studied that showed a decrease in ${ }^{18} \mathrm{~F}$-FDG-uptake after chronic MPH administration. It is a subregion of the rat prefrontal cortex [70], which is responsible for evaluating the interpretation of threat and adjust the anxiety response accordingly [71]. Also, the rat orbitofrontal cortex includes distinct subregions: medial orbital area, ventral orbital area, lateral orbital area, and dorsolateral orbital area [72-74] and has multiple connections with sensory systems such as hippocampus and amygdala $[75,76]$. In this context, analysis of the ${ }^{18} \mathrm{~F}-\mathrm{FDG}$ uptake in hippocampus, following chronic MPH treatment revealed no significant effect; however, there was a trend towards a decreased glucose metabolism in the left posterior hippocampus $(p=0.054)$. Zhang et al. [45] showed that the uptake of ${ }^{18} \mathrm{~F}-\mathrm{FDG}$ in the cerebellum of young adult male rhesus monkeys was significantly decreased after a long treatment when compared to the control group. Since cerebral glucose hypometabolism has been associated with impairment in energy metabolism, as well as with the pathophysiology of neuropsychiatric diseases $[77,78]$, our result found suggests that chronic MPH treatment could impairs the left orbitofrontal cortex activity, affecting its role in brain activities. 
Based on classic notions of neuroenergetics, it is a consensus that cerebral ${ }^{18} \mathrm{~F}-\mathrm{FDG}$ metabolism indicates brain energy consumption and, thus, brain activity [69, 79], as well as allows the identification of interregional connections as an index of the functional metabolic architecture of the brain [80]. In order to identify whether the ${ }^{18} \mathrm{~F}-\mathrm{FDG}$ metabolism changes observed affect at the network level, we decided to analyze the cerebral metabolic network in chronic MPH treated rats through microPET. The regions included in the metabolic network analysis were selected because they play an important role in the pathophysiology of ADHD and/or MPH mechanisms and/or presented ${ }^{18} \mathrm{~F}$-FDG-uptake changed in this study. We observed that chronic MPH treatment promotes hypersynchronicity in the metabolic network of the brain. Compared to control, the MPH group shows an increased number of significant connections, which was confirmed by the density graph measure. Likewise, the increase of global efficiency entails that overall region-to-region exchange of information is more efficient for the MPH treated rats. In addition, the significant increase in the assortativity coefficient, as well as in the average clustering coefficient, indicate that MBNs of the MPH group tend to be more resilient (i.e. less vulnerable to gradual deterioration) and to have more specialized processing brain regions [61]. However, careful analyzes of the correlation matrices reveal that the MPH interrupts the connection of the orbitofrontal cortex with other brain areas, which is in agreement with the decrease in ${ }^{18} \mathrm{~F}$-FDG-uptake. Similar to our findings, van der Marel and colleagues [81] have also showed that chronic MPH treatment affected the topological characteristics of the metabolic networks in young and adult rats.

The lateralization of the effects promoted by MPH on the brain glucose metabolism and the metabolic network in chronically MPH-treated rats is very interesting. Hemispheric asymmetries are evident in the anatomy, cytoarchitecture and neurochemistry of the vertebrate brain [82-84]. Studies have shown that a number of cognitive abilities rely heavily on lateralized processing in the human brain, with the most widely investigated being language and visuo-spatial processing [85]. Other domains relying on lateralized brain functionality include: emotional processing [86], fine motor skills [87], and memory [88], as well as face and body perception [89]. Abnormal structural asymmetries have been reported in Parkinson's disease, schizophrenia, and Alzheimer's disease $[84,90]$. In this study, although we found changes in glucose uptake on both the left and right sides, these changes were more pronounced on the left side, suggesting that the mechanisms/effects of MPH are lateralized. This finding is consistent with a previous clinical study which has also shown that MPH may have a more pronounced effect on neurochemicals in the left frontal cortex and left striatum [91]. Further investigations may establish the clinical relevance of these findings.

Many anxiety-like and depression-like behaviors were significantly correlated with glucose metabolism changes in structures with a pivotal role in depression and anxiety [27]. In order to identify whether the glucose brain metabolism and metabolic network changes caused by chronic MPH administration in juvenile rats observed in this study coincides with anxiety-like and depression-like behavior, we evaluated the performance in the light-dark transition box, eating-related depression, and sucrose preference tests.

Similar to our previous report when we showed that juvenile rats treated with MPH explored less the open arms in the elevated plus maze and the environment in the open field test [51], we observed that MPH- 
treated rats spend less time in light box, suggesting that MPH treatment evoked an anxiety-like behavior. Corroborating our findings, Britton and Bethancourt [92] show that MPH treatment at doses of 3 and 5 $\mathrm{mg} / \mathrm{kg}$ elicited a significant decrement in locomotor behavior in the open field test and MPH treatment at a dose of $2 \mathrm{mg} / \mathrm{kg}$ increased anxiety in the light-dark transition test as evidenced by less time spent in the light compartment relative to controls. In addition, this result could be related to the decrease in glucose metabolism and reshaping of the metabolic network impairment observed in the orbitofrontal cortex, since this brain region is involved in the psychological and neurobiological processes of anxiety and their interruption in pathological anxiety [93]. Corroborating this, studies have found increased responses to fear in rodents injured in the orbitofrontal cortex $[94,95]$ and increased anxiety displayed by injured non-human primates in the orbitofrontal cortex [74].

The performance of MPH-treated rats on sucrose preference test, a tool to analyze anhedonia, a depressive-like behavior and in the eating-related depression test was assessed. Interestingly, contrary to what we initially expected, the animals treated with MPH showed a greater sensitivity to the positive reinforcement promoted by sucrose when compared to the control group. We also did not observe any depressive-like behavior from the eating-related depression test. However, these data is in agreement with previous studies that have provided evidence for an anti-depressive effect of MPH [96-99]. Hardy [100] even demonstrated the effectiveness of MPH in treating symptoms similar to depression in humans. On the other hand, there are reports of a depressive effect of MPH in rodents [37, 40,101-104]. The increase in positive reinforcement by sucrose triggered by MPH is quite interesting, since suggests this psychostimulant as a potential therapeutic agent in the treatment of obesity or chemical dependency, for example, replacing the positive reinforcement obtained through the cafeteria diet and drug abuse. On the other hand, the increase in positive reinforcement to other substances may favor the development of chemical dependence by normal individuals in cases of non-medical use of MPH. Corroborating this, Vendruscolo and colleagues [40] showed that chronic treatment with MPH (2 mg/kg intraperitoneally; twice daily for 16 days) enhanced ethanol intake.

The understanding of the consequences of chronic treatment with MPH on early stages of brain development is very important since this psychostimulant has been used extensively in preschool age children and young adults who do not meet full diagnostic criteria for $\operatorname{ADHD}[5-9,105,106]$. This is of great concern to neuroscientists since it has been described that the interruption of brain connectivity causes cell death in the immature brain more rapidly and with higher frequency than in the mature brain $[107,108]$. Also, there is evidence that early-life exposure to MPH induces long-lasting behavioral adaptations [109]. In line with this, studies show that adult rats submitted to chronic treatment with psychostimulants during childhood and adolescence present changes in neurochemical, behavioral, and molecular parameters $[102,110-113]$. In this context, alteration in dopaminergic system, redox status, mitochondrial function, glutamatergic/GABAergic systems, neuroinflammation, blood-brain barrier, and neurogenesis have been associated with MPH treatment [105, 114-117]. Here, we provide some novel insights into the biochemical and behavioral effects of $\mathrm{MPH}$ on the adolescent brain. For this purpose, ${ }^{18}$ F-FDG-microPET scan was employed to analyze the left and right cerebral hemispheres of rats that 
have not been genetically manipulated. The effects of MPH observed in the present study could be related to the mechanism of action of the drug in the adolescent brain. These findings also show evidence of the potential of early MPH exposure to modify emotional responses, as well as contribute new information that has implications for the neurobiological understanding of anxiety, and by extension, to the future development of more directed/specific pharmacological treatments for anxiety disorders.

Summing up, we showed that MPH caused changes in glucose uptake in several regions of the brain. Further, there were lateralization alterations in the ${ }^{18} \mathrm{~F}$-FDG uptake in specific brain regions, indicating that left side could be more sensitive to the MPH effects. Also, MPH-treated rats show a brain metabolic network more efficient and connected. However, unlike most of the brain regions analyzed, the orbitofrontal cortex shows glucose hypometabolism and impaired metabolic network connectivity and efficiency, which probably may be related to the observed anxious behavior, since this region of the brain is involved in psychological and neurobiological processes of anxiety (Fig. 7). As far as we know, this is the first study showing the relationship among changes in glucose metabolism with the brain metabolic network and the behavioral changes in juvenile rats submitted to early chronic treatment with a clinically relevant dose of MPH. We chose to study the effect of MPH only in male rats because there are several studies showing that this drug is used more in boys than in girls [118-122]. However, further work needs to be done to determine the effects that MPH may cause on females. Finally, in view of the marked increase in MPH consumption over the past decade, vigilance is crucial in order to prevent potential drug abuse and its long-term detrimental consequences.

\section{Abbreviations}

ADHD, attention-deficit/hyperactivity disorder

CNS, central nervous system

DA, dopamine

DAT, dopamine transporter

${ }^{18}$ F-FDG, fluorodeoxyglucose- 18

FDR, false discovery rate

MBN, metabolic brain network

$\mathrm{MPH}$, methylphenidate

microPET, micro positron emission tomography

$\mathrm{NE}$, norepinephrine

NET, norepinephrine transporter 
PET, positron emission tomography

SUV, standardized uptake value

SUVr, standardized uptake value ratio

VOI, volume of interest

\section{Declarations}

\section{Acknowledgments}

This study was supported by Instituto Nacional de Ciência e Tecnologia em Excitotoxicidade e Neuroproteção (INCT-EN) (grant number no. 465671/2014-4), Conselho Nacional de Desenvolvimento Científico e Tecnológico (CNPq) , Fundação de Amparo à Pesquisa do Estado do Rio Grande do Sul (FAPERGS) (grant number no. 16/0465-0), and Fundação Coordenação de Aperfeiçoamento de Pessoal de Nível Superior (CAPES), Brazil.

\section{Compliance with ethical standards}

\section{Conflict of interest}

The authors declare that they have no known competing financial interests or personal relationships that could have appeared to influence the work reported in this paper.

\section{Ethics approval}

All animal experimental procedures were approved by the Institutional Ethics Committee on Animal Use (No. 37027) and were in accordance with the National Institutes of Health guide for the care and use of Laboratory animals (NIH Publications No. 80-23, revised 1996), the guide of the Federation of Brazilian Societies for Experimental Biology and the Arouca Law ( $\left.n^{\circ} 11.794 / 2008\right)$.

\section{Consent to participate}

Not applicable

\section{Consent to Publication}

Not applicable

\section{Availability of data material}

Not applicable

\section{Author contributions}


F. S. and A. T. S. W. designed the studies. G. T. V., S. G., J. C. C. contributed to the MicroPET data collection. G. G. S. P. and E. R. Z. contributed to the metabolic network data collection. F. S. and J. S. S. contributed to the behavioral data collection. F. S., A. T. S. W. and E. R. Z. analyzed and interpreted the work. F. S. and A. T. S. W. wrote the manuscript. All authors have read, revised and approved the final version of this manuscript.

\section{ORCID ID}

Felipe Schmitz https://orcid.org/0000-0002-9746-0286

Angela TS Wyse: https://orcid.org/0000-0001-8769-1147

Eduardo R. Zimmer https://orcid.org/0000-0002-5349-0053

Gianina Teribele Venturin https://orcid.org/0000-0001-7696-8219

Samuel Greggio https://orcid.org/0000-0002-5187-0335

Jaderson Costa Da Costa https://orcid.org/0000-0001-6776-1515

Josiane Silva Ferreira https://orcid.org/0000-0002-9725-2209

\section{References}

[1]. National Institute for Health and Care Excellence (2018) Attention Deficit Hyperactivity Disorder: Diagnosis and Management.

[2]. American Psychiatric Association (2013) Diagnostic and Statistical Manual of Mental Disorders. Washington, DC.

[3]. Centers for Disease Control and Prevention (2013) Mental Health Surveillance AmongChildren United States, 2005-2011.

[4]. Polanczyk GV, Willcutt EG, Salum GA et al (2014) ADHD prevalence estimates across three decades: an updated systematic review and meta-regression analysis. Int J Epidemiol 43:434-442.

[5]. Clemow DB (2017) Misuse of methylphenidate. Curr Top Behav Neurosci 34:99-124.

[6]. Jensen LS, Pagsberg AK, Dalhoff K (2015) Methylphenidate misuse in adult patients and the impact of therapeutic use. Hum Exp Toxicol 34:460-467.

[7]. Kim MG, Kim J, Kim SC et al (2020) Twitter Analysis of the Nonmedical Use and Side Effects of Methylphenidate: Machine Learning Study. J Med Internet Res 22:e16466. 
[8]. Rowland SA, Lesesne CA, Abramowitz AJ (2002) The epidemiology of attention-deficit/hyperactivity disorder (ADHD): a public health view. Ment Retard Dev Disabil Res Rev 8:162-170.

[9]. Zito JM, Safer DJ, dos Reis S et al (2000) Trends in the prescribing of psychotropic medications to preschoolers. JAMA 283:1025-1030.

[10]. Challman TD, Lipsky JJ (2000) Methylphenidate: its pharmacology and uses. Mayo Clin Proc 7:711-721.

[11]. Grünblatt E, Bartl J, Marinova Z et al (2013) In vitro study methodologies to investigate genetic aspects and effects of drugs used in attention-deficit hyperactivity disorder. J Neural Transm 120:131139.

[12]. Gumustas F, Yilmaz I, Sirin DY et al (2017) Chondrocyte proliferation, viability and differentiation is declined following administration of methylphenidate utilized for the treatment of attention-deficit/ hyperactivity disorder. Hum Exp Toxicol 36:981-992.

[13]. Kuczenski R, Segal DS (2001) Locomotor effects of acute and repeated threshold doses of amphetamine and methylphenidate: relative roles of dopamine and norepinephrine. J Pharmacol Exp Ther 296:876-883.

[14]. Schmeichel BE, Zemlan FP, Berridge CW (2013) A selective dopamine reuptake inhibitor improves prefrontal cortex-dependent cognitive function: potential relevance to attention deficit hyperactivity disorder. Neuropharmacology 64:321-328.

[15]. Volkow ND, Wang G, Fowler JS et al (2001) Therapeutic doses of oral methylphenidate significantly increase extracellular dopamine in the human brain. J Neurosci 21:1-5.

[16]. Amara SG, Kuhar MJ (1993) Neurotransmitter transporters: recent progress. Annu Rev Neurosci 16:73-93.

[17]. Martin TA, Smith HR, Luessen DJ et al (2019) Functional brain activity is globally elevated by dopamine D2 receptor knockdown in the ventral tegmental area. Brain Research doi: https://doi.org/10.1016/j.brainres.2019.146552

[18]. Mitelman AS, Buchsbaum MS, Christian BT et al (2020) Positive association between cerebral grey matter metabolism and dopamine D2/D3 receptor availability in healthy and schizophrenia subjects: an 18F-fluorodeoxyglucose and 18F-fallypride positron emission tomography study. World J Biol Psychiatry 21:368-382.

[19]. Comim CM, Gomes KM, Réus GZ et al (2014) Methylphenidate treatment causes oxidative stress and alters energetic metabolism in an animal model of attention-deficit hyperactivity disorder. Acta Neuropsychiatr 26:96-103. 
[20]. Fagundes AO, Rezin GT, Zanette F et al (2007) Chronic administration of methylphenidate activates mitochondrial respiratory chain in brain of young rats. Int J Dev Neurosci 25:47-51.

[21]. Réus GZ, Scaini G, Furlanetto CB et al (2013) Methylphenidate treatment leads to abnormalities on krebs cycle enzymes in the brain of young and adult rats. Neurotox Res 24:251-257.

[22]. Scaini G, Fagundes AO, Rezin GT et al (2008) Methylphenidate increases creatine kinase activity in the brain of young and adult rats. Life Sci 83: 795-800.

[23]. Banerjee PS, Aston J, Khundakar AA (2009) Differential regulation of psychostimulant-induced gene expression of brain derived neurotrophic factor and the immediate-early gene Arc in the juvenile and adult brain. Eur J Neurosci 29::465-476.

[24]. Gronier B, Aston J, Liauzun C et al (2010) Age-dependent effects of methylphenidate in the prefrontal cortex: evidence from electrophysiological and Arc gene expression measurements. J. Psychopharmacol Oxf Engl 24:1819-1827.

[25]. Yano M, Steiner H (2007) Methylphenidate and cocaine: the same effects on gene regulation? Trends Pharmacol Sci 28:588-596.

[26]. Schmitz F, Pierozan P, Rodrigues AF et al (2016a) Methylphenidate decreases ATP levels and impairs glutamate uptake and $\mathrm{Na}^{+}, \mathrm{K}^{+}$-ATPase activity in juvenile rat hippocampus. Mol Neurobiol 4:7796-7807.

[27]. Hu H, Su L, Xu YQ et al (2010) Behavioral and [F-18] fluorodeoxyglucose micro positron emission tomography imaging study in a rat chronic mild stress model of depression. Neuroscience 169:171-181.

[28]. Bailer UF, Narendran R, Frankle WG et al (2012) Amphetamine induced dopamine release increases anxiety in individuals recovered from anorexia nervosa. Int J Eat Disord 45:263-271.

[29]. Goddard AW, Ball SG, Martinez J et al (2010) Current perspectives of the roles of the central norepinephrine system in anxiety and depression. Depress Anxiety 27:339-350.

[30]. Kacprzak V, Patel NA, Riley E et al (2017) Dopaminergic control of anxiety in young and aged zebrafish. Pharmacol Biochem Behav 157:1-8.

[31]. Yorgason JT, España RA, Konstantopoulos JK et al (2013) Enduring increases in anxiety-like behavior and rapid nucleus accumbens dopamine signaling in socially isolated rats. Eur $\mathrm{J}$ Neurosci 37:1022-1031.

[32]. Baculis BC, Diaz MR, Valenzuela CF (2015) Third trimester-equivalent ethanol exposure increases anxiety-like behavior and glutamatergic transmission in the basolateral amygdala. Pharmacol Biochem Behav 137:78-85. 
[33]. Leret ML, Millán JA, Antonio MT (2003) Perinatal exposure to lead and cadmium affects anxiety-like behaviour. Toxicology 186:125-130.

[34]. Matsuda S, Matsuzawa D, Ishii D et al (2012) Effects of perinatal exposure to low dose of bisphenol A on anxiety like behavior and dopamine metabolites in brain. Prog Neuro-Psychopharmacol Biol Psychiatry 39:273-279.

[35]. Zhou R, Wang S, Zhu X (2010) Prenatal ethanol exposure attenuates GABAergic inhibition in basolateral amygdala leading to neuronal hyperexcitability and anxiety-like behavior of adult rat offspring. Neuroscience 170:749-757.

[36]. Liu S, Yu M, Xie X et al (2020) Carbofuran induces increased anxiety-like behaviors in female zebrafish (Danio rerio) through disturbing dopaminergic/norepinephrinergic system. Chemosphere 253:126635 doi: 10.1016/j.chemosphere.2020.126635.

[37]. Bolaños CA, Barrot M, Berton $O$ et al (2003) Methylphenidate treatment during pre- and periadolescence alters behavioral responses to emotional stimuli at adulthood. Biol Psychiatry 54:13171329.

[38]. Gray JD, Punsoni M, Tabori NE et al (2007) Methylphenidate administration to juvenile rats alters brain areas involved in cognition, motivated behaviors, appetite, and stress. J Neurosci. 27:7196-7207.

[39]. LeBlanc-Duchin D, Taukulis HK (2007) Chronic oral methylphenidate administration to periadolescent rats yields prolonged impairment of memory for objects. Neurobiol Learn Mem. 88:312320 .

[40]. Vendruscolo LF, Izídio GS, Takahashi RN et al (2008) Chronic methylphenidate treatment during adolescence increases anxiety-related behaviors and ethanol drinking in adult spontaneously hypertensive rats. Behav Pharmacol 19:21-27.

[41]. Bruchmuller K, Margraf J, Schneider S (2012) Is ADHD diagnosed in accord with diagnostic criteria? Overdiagnosis and influence of client gender on diagnosis. J Consult Clin Psychol 80:128-138.

[42]. Evans WN, Morrill MS, Parente ST (2010) Measuring inappropriate medical diagnosis and treatment in survey data: the case of ADHD among school-age children. J Health Econ 29:657-673.

[43]. Klein-Schwartz W (2003) Pediatric methylphenidate exposures: 7-year experience of poison centers in the United States. Clin. Pediatr. (Phila.) 42:159-164.

[44]. Simchon-Tenenbaum Y, Weizman A, Rehavi M (2015) Alterations in brain neurotrophic and glial factors following early age chronic methylphenidate and cocaine administration. Behav Brain Res 282:125-132. 
[45]. Zhang X, Newport GD, Callicott R et al (2016) MicroPET/CT assessment of FDG uptake in brain after long-term methylphenidate treatment in nonhuman primates. Neurotoxicol Teratol 56:68-74.

[46]. Zhang X, Yon Q, Berridge M et al (2018) Application of molecular imaging technology in neurotoxicology research. J Environ Sci C Environ Carcinog Ecotoxicol Rev 36:113-124.

[47]. Scherer EB, da Cunha MJ, Matté C et al (2010) Methylphenidate affects memory, brain-derived neurotrophic factor immunocontent and brain acetylcholinesterase activity in the rat. Neurobiol Learn Mem 94:247-253.

[48]. Schmitz F, Scherer EB, da Cunha MJ et al (2012a) Chronic methylphenidate administration alters antioxidant defenses and butyrylcholinesterase activity in blood of juvenile rats. Mol Cell Biochem 361:281-28.

[49]. Schmitz F, Scherer EB, Machado FR (2012b) Methylphenidate induces lipid and protein damage in prefrontal cortex, but not in cerebellum, striatum, and hippocampus of juvenile rats. Metab Brain Dis 27:605-612.

[50]. Schmitz F, Pierozan P, Rodrigues AF et al (2015) Chronic treatment with a clinically relevant dose of methylphenidate increases glutamate levels in cerebrospinal fluid and impairs glutamatergic homeostasis in prefrontal cortex of juvenile rats. Mol Neurobiol 53:2384-2396.

[51]. Schmitz F, Pierozan P, Rodrigues AF et al (2016b) Methylphenidate causes behavioral impairments and neuron and astrocyte loss in the hippocampus of juvenile rats. Mol Neurobiol 54:4201-4216.

[52]. Schmitz F, Pierozan P, Biasibetti-Brendler $\mathrm{H}$ et al (2018) Methylphenidate disrupts cytoskeletal homeostasis and reduces membrane-associated lipid content in juvenile rat hippocampus. Metab Brain Dis 33:693-704.

[53]. Gerasimov MR, Franceschi M, Volkow ND et al (2000) Comparison between intraperitoneal and oral methylphenidate administration: a microdialysis and locomotor activity study. J Pharmacol Exp Ther 295:51-57.

[54]. Rice D, Barone SJr (2000) Critical periods of vulnerability for the developing nervous system: evidence from humans and animal models. Environ Health Perspect 108:511-533.

[55]. Andreazza AC, Frey BN, Valvassori SS et al (2007) DNA damage in rats after treatment with methylphenidate. Prog Neuropsychopharmacol Biol Psychiatry 31:1282-1288.

[56]. Baptista PPA, Saur L, Bagatini PB et al (2015) Antidepressant effects of ketamine are not related to $\triangle$ $\triangle F-F D G$ metabolism or tyrosine hydroxylase immunoreactivity in the ventral tegmental area of Wistar rats. Neurochem Res 40:1153-1164. 
[57]. Zanirati G, Azevedo PN, Venturin GT et al (2018) Depression comorbidity in epileptic rats is related to brain glucose hypometabolism and hypersynchronicity in the metabolic network architecture. Epilepsia 59:923-934.

[58]. Bellaver B, Rocha AS, Souza DG et al (2019) Activated peripheral blood mononuclear cell mediators trigger astrocyte reactivity. Brain Behav Immun 80:879-888.

[59]. Silva RBM, Greggio S, Venturin GT et al (2018) Beneficial effects of the calcium channel blocker CTK 01512-2 in a mouse model of multiple sclerosis. Mol Neurobiol 55:9307-9327.

[60]. Benjamini Y, Hochberg Y (1995) Controlling the false discovery rate: A practical and powerful approach to multiple testing. Journal of the Royal Statistical Society. Serie B 57:289-300.

[61]. Rubinov M, Sporns O (2010) Complex network measures of brain connectivity: uses and interpretations. Neurolmage 52:1059-1069.

[62]. Takao K, Miyakawa T (2006) Light/dark transition test for mice. J Vis Exp 13:104.

[63]. Upadhya D, Hattiangady B, Shetty GA et al (2016) Neural stem cell or human induced pluripotent stem cell-derived GABA-ergic progenitor cell grafting in an animal model of chronic temporal lobe epilepsy. Curr Protoc Stem Cell Biol 38:2D.7.1-2D.7.47

[64]. Réus GZ, Scaini G, Titus SE et al (2015) Methylphenidate increases glucose uptake in the brain of young and adult rats. Pharmacol Rep 67:1033-1040.

[65]. Berridge CW, Devilbiss DM, Andrzejewski ME et al (2006) Methylphenidate Preferentially Increases Catecholamine Neurotransmission within the Prefrontal Cortex at Low Doses that Enhance Cognitive Function. Biol Psychiatry 60:1111-1120.

[66]. Brus R, Szkilnik R, Kostrzewa RM et al (1995). Modulation of glucose uptake in rat brain after administration of quinpirole and SKF 38393, two central dopamine receptor agonists. Pharmacol Comm 7:87-91.

[67]. Szkilnik R, Ooewiêcimska J, brus R et al (1999) Modulation of glucose uptake in rat's brain, heart, liver and kidneys, after administration of quinpirole and 7-OH-DPAT, two central dopamine-D receptor agonists. Pharmacol Comm 10:325-8.

[68]. Nowak P, Swoboda M, Szkilnik R et al (2007) Nitric oxide modulates the amphetamine effect on [3H]glucose uptake in the brain of rats prenatally exposed to lead. Pharmacol Rep 59:601-605.

[69]. Kim YW, Shin JC, An YS (2009) Effects of methylphenidate on cerebral glucose metabolism in patients with impaired consciousness after acquired brain injury. Clin Neuropharmacol 32:335-339. 
[70]. Hoover WB, Vertes RP (2007) Anatomical analysis of afferent projections to the medial prefrontal cortex in the rat. Brain Struct Funct 212:149-179.

[71]. Calhoon GG, Tye KM (2015) Resolving the neural circuits of anxiety. Nat Neurosci 18:1394-1404.

[72]. Izquierdo A (2017) Functional heterogeneity within rat orbitofrontal cortex in reward learning and decision making. J Neurosci 37:10529-10540.

[73]. Kuniishi H, Ichisaka S, Matsuda S et al (2017) Chronic inactivation of the orbitofrontal cortex increases anxiety-like behavior and impulsive aggression, but decreases depressionlike behavior in rats. Front Behav Neurosci 10:250.

[74]. Shiba Y, Santangelo AM, Roberts AC (2016) Beyond the medial regions of prefrontal cortex in the regulation of fear and anxiety. Front Syst Neurosci 10:12.

[75]. Kalin NH, Shelton SE, Davidson RJ (2007) Role of the primate orbitofrontal cortex in mediating anxious temperament. Biol Psychiatry 62:1134-1139.

[76]. Wallis JD (2011) Cross-species studies of orbitofrontal cortex and value based decision-making. Nat Neurosci 15:13-19.

[77]. Tenney JR, Rozhkov L, Horn P et al (2014) Cerebral glucose hypometabolism is associated with mitochondrial dysfunction in patients with intractable epilepsy and cortical dysplasia. Epilepsia 55:1415-22.

[78]. Zimmer L (2009) Positron emission tomography neuroimaging for a better understanding of the biology of ADHD. Neuropharmacology 57:601-607.

[79]. Wang D, Li X, Gao K et al (2013) Cardiotrophin-1 (CTF1) ameliorates glucose-uptake defects and improves memory and learning deficits in atransgenic mouse model of Alzheimer's disease. Pharmacol Biochem Behav 107:48-57.

[80]. Zimmer ER, Parent MJ, Souza DG et al (2017). [18F]FDG PET signal is driven by astroglial glutamate transport. Nat Neurosci. 20:393-395.

[81]. van der Marel K, Bouet V, Meerhoff GF et al (2015) Effects of long-term methylphenidate treatment in adolescent and adult rats on hippocampal shape, functional connectivity and adult neurogenesis. Neuroscience 309:243-258.

[82]. Altarelli I, Leroy F, Monzalvo K et al (2014) Planum temporale asymmetry in developmental dyslexia: Revisiting an old question. Hum Brain Mapp 35:5717-5735.

[83]. Toga AW, Thompson PM (2003) Mapping brain asymmetry. Nat Rev Neurosci 4:37-48 
[84]. Wang J, Yang QX, Sun X et al (2015) MRI evaluation of asymmetry of nigrostriatal damage in the early stage of early-onset Parkinson's disease. Parkinsonism Relat Disord 21:590-596.

[85]. Corballis MC (2009) The evolution and genetics of cerebral asymmetry. Philos Trans R Soc Lond B Biol Sci 364:867-879.

[86]. Onal-Hartmann C, Pauli P, Ocklenburg S et al (2012) The motor side of emotions: investigating the relationship between hemispheres, motor reactions and emotional stimuli. Psychol Res 76:311-316.

[87]. Arning L, Ocklenburg S, Schulz S (2013) PCSK6 VNTR polymorphism is associated with degree of handedness but not direction of handedness. PLoS ONE 8:e67251.

[88]. Habib R, Nyberg L, Tulving E (2003) Hemispheric asymmetries of memory: the HERA model revisited. Trends Cogn Sci 7:241-245.

[89]. Thoma P, Bauser DS, Norra C (2014) Do you see what I feel?-Electrophysiological correlates of emotional face and body perception in schizophrenia. Clin Neurophysiol 125:1152-1163

[90]. Derflinger S, Sorg C, Gaser C et al (2011) Grey-matter atrophy in Alzheimer's disease is asymmetric but not lateralized. J Alzheimers Dis 25:347-357.

[91]. Ben Amor L (2014) 1 H-Magnetic resonance spectroscopy study of stimulant medication effect on brain metabolites in French Canadian children with attention deficit hyperactivity disorder. Neuropsychiatr Dis Treat 10:47-54.

[92]. Britton GB, Bethancourt JA (2009) Characterization of anxiety-related responses in male rats following prolonged exposure to therapeutic doses of oral methylphenidate. Pharmacol Biochem Behav 93:451-459.

[93]. Grupe DW, Nitschke JB (2013) Uncertainty and anticipation in anxiety: an integrated neurobiological and psychological perspective. Nat Rev Neurosci 14:488-501.

[94]. Lacroix L, Spinelli S, Heidbreder CA et al (2000) Differential role of the medial and lateral prefrontal cortices in fear and anxiety. Behav Neurosci 114:1119-1130.

[95]. Zelinski EL, Hong NS, Tyndall AV et al (2010) Prefrontal cortical contributions during discriminative fear conditioning, extinction, and spontaneous recovery in rats. Exp Brain Res 203:285-297.

[96].Golubchik P, Rapaport M, Weizman A (2017) The effect of methylphenidate on anxiety and depression symptoms in patients with Asperger syndrome and comorbid attention deficit/hyperactivity disorder. Int Clin Psychopharmacol. 32:289-293.

[97]. Homsi J, Nelson KA, Sarhill N et al (2001) A phase Il study of methylphenidate for depression in advanced cancer. Am J Hosp Palliat Care 18:403-407. 
[98]. Kerr CW, Drake J, Milch RA et al (2012) Effects of methylphenidate on fatigue and depression: a randomized, double-blind, placebo-controlled trial. J Pain Symptom Manage 43:68-77.

[99]. Lazarus LW, Moberg PJ, Langsley PR et al (1994) Methylphenidate and nortriptyline in the treatment of poststroke depression: a retrospective comparison. Arch Phys Med Rehabil 75:403-406.

[100]. Hardy SE (2009) Methylphenidate for the treatment of depressive symptoms, including fatigue and apathy, in medically ill older adults and terminally ill adults. Am J Geriatr Pharmacother 7:34-59.

[101]. Brookshire BR, Jones SR (2012) Chronic methylphenidate administration in mice produces depressive-like behaviors and altered responses to fluoxetine. Synapse 66:844-847.

[102]. Carlezon WAJr, Mague SD, Andersen SL (2003) Enduring behavioral effects of early exposure to methylphenidate in rats. Biol Psychiatry 54:1330-1337.

[103]. Motaghinejad M, Motevalian M, Ebrahimzadeh A et al (2015a) Reduction of methylphenidate induced anxiety, depression and cognition impairment by various doses of venlafaxine in rat. Int J Prev Med. 6:52

[104]. Motaghinejad M, Montevalian M, Larijani SF (2015b) Protective effects of forced exercise against methylphenidate-induced anxiety, depression and cognition impairment in rat. Adv Biomed Res. 4:134.

[105]. Gonçalves J, Baptista S, Silva AP (2014) Psychostimulants and brain dysfunction: a review of the relevant neurotoxic effects. Neuropharmacology 87:135-149.

[106]. Loureiro-Vieira S, Costa VM, de Lourdes Bastos M et al (2017) Methylphenidate effects in the young brain: friend or foe? Int J Dev Neurosci 60:34-47.

[107]. Kudryashov IE, Onufriev MV, Kudryashova IV et al (2001) Periods of postnatal maturation of hippocampus: synaptic modifications and neuronal disconnection. Dev Brain Res 132:113-120.

[108]. Nyakas C, Buwalda B, Luiten PG (1996) Hypoxia and brain development. Prog Neurobiol 49:1-51.

[109]. Wiley MD, Poveromo LB, Antapasis J et al (2009) Kappa-opioid system regulates the long-lasting behavioral adaptations induced by early-life exposure to methylphenidate. Neuropsychopharmacology 34:1339-1350.

[110]. Adriani W, Leo D, Greco D et al (2006) Methylphenidate administration to adolescent rats determines plastic changes on reward-related behavior and striatal gene expression. Neuropsychopharmacology 31:1946-1956.

[111]. Andersen SL, Arvanitogiannis A, Pliakas AM et al (2002) Altered responsiveness to cocaine in rats exposed to methylphenidate during development. Nat Neurosci 5:13-14. 
[112]. Carlezon WAJr, Konradi C (2004) Understanding the neurobiological consequences of early exposure to psychotropic drugs: linking behavior with molecules. Neuropharmacology 47:47-60.

[113]. Mague SD, Andersen SL, Carlezon WAJr (2005) Early developmental exposure to methylphenidate reduces cocaine-induced potentiation of brain stimulation reward in rats. Biol Psychiatry 57:120-125.

[114]. Lagace DC, Yee JK, Bolaños CA et al (2006) Juvenile administration of methylphenidate attenuates adult hippocampal neurogenesis. Biol Psychiatry 60:1121-1130.

[115]. Motaghinejad M, Motevalian M, Shabbab B (2016) Effects of chronic treatment with methylphenidate on oxidative stress and inflammation in hippocampus of adult rats. Neurosci Lett 619:106-113.

[116]. Réus GZ, Scaini G, Jeremias GC et al (2014) Brain apoptosis signaling pathways are regulated by methylphenidate in young and adult rats. Brain Res 1583:269-276.

[117]. Sadasivan S, Pond BB, Pani AK (2012) Methylphenidate exposure induces dopamine neuron loss and activation of microglia in the basal ganglia of mice. PLoS One 7:e33693

[118]. Bauermeister JJ, Shrout PE, Chávez L et al (2007) ADHD and gender: are risks and sequela of ADHD the same for boys and girls? J Child Psychol Psychiatry 48:831-839.

[119]. Park JH, Bang YR, Kim CK (2014) Sex and Age Differences in Psychiatric Disorders among Children and Adolescents: High-Risk Students Study. Psychiatry Investig 11:251-7.

[120]. Ehehardt C, Boucherie Q, Pauly V et al (2017) Methylphenidate: Gender trends in adult and pediatric populations over a 7year period. Therapie 72:635-641.

[121]. Bouziane C, Filatova OG, Schrantee A et al (2019) White Matter by Diffusion MRI Following Methylphenidate Treatment: A Randomized Control Trial in Males with Attention-Deficit/Hyperactivity Disorder. Radiology 293:186-192.

[122]. Efron D, Mulraney M, Sciberras E et al (2020) Patterns of long-term ADHD medication use in Australian children. Arch Dis Child 105:593-597.

\section{Figures}




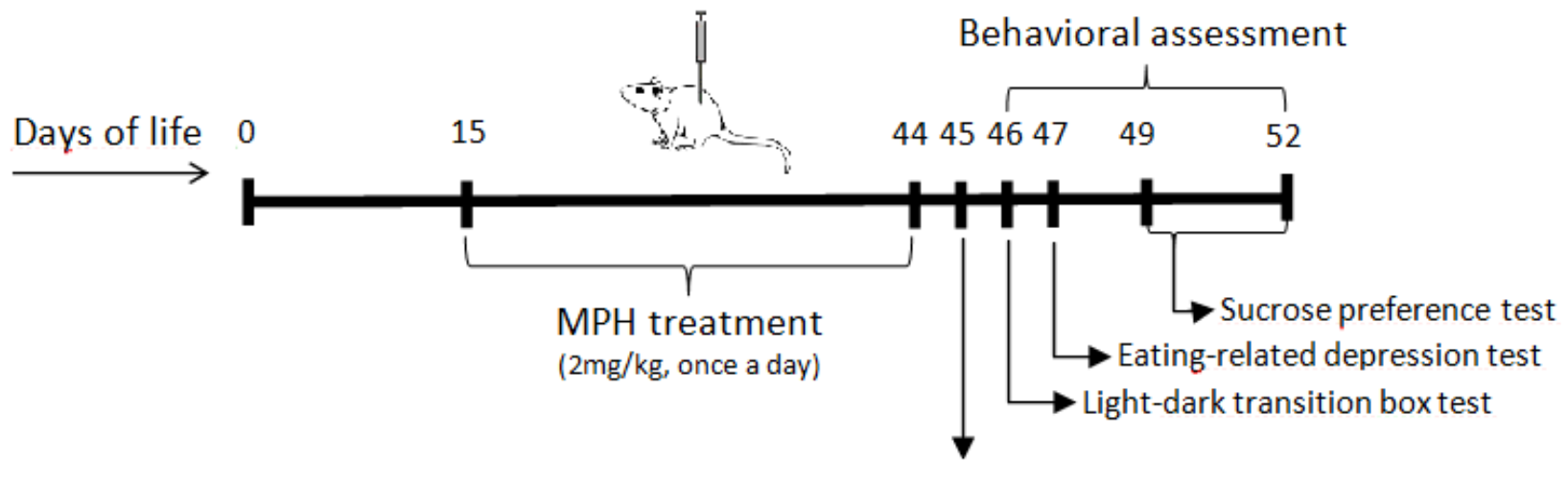

MicroPET imaging

\section{Figure 1}

Study design. Thirty days of MPH administration. Twenty-four hours after last injection, MicroPET imaging was performed. Then, anxiety and depression related behavioral tests were performed from 46 to 52 days of life. MPH, methylphenidate; microPET, positron emission microtomography
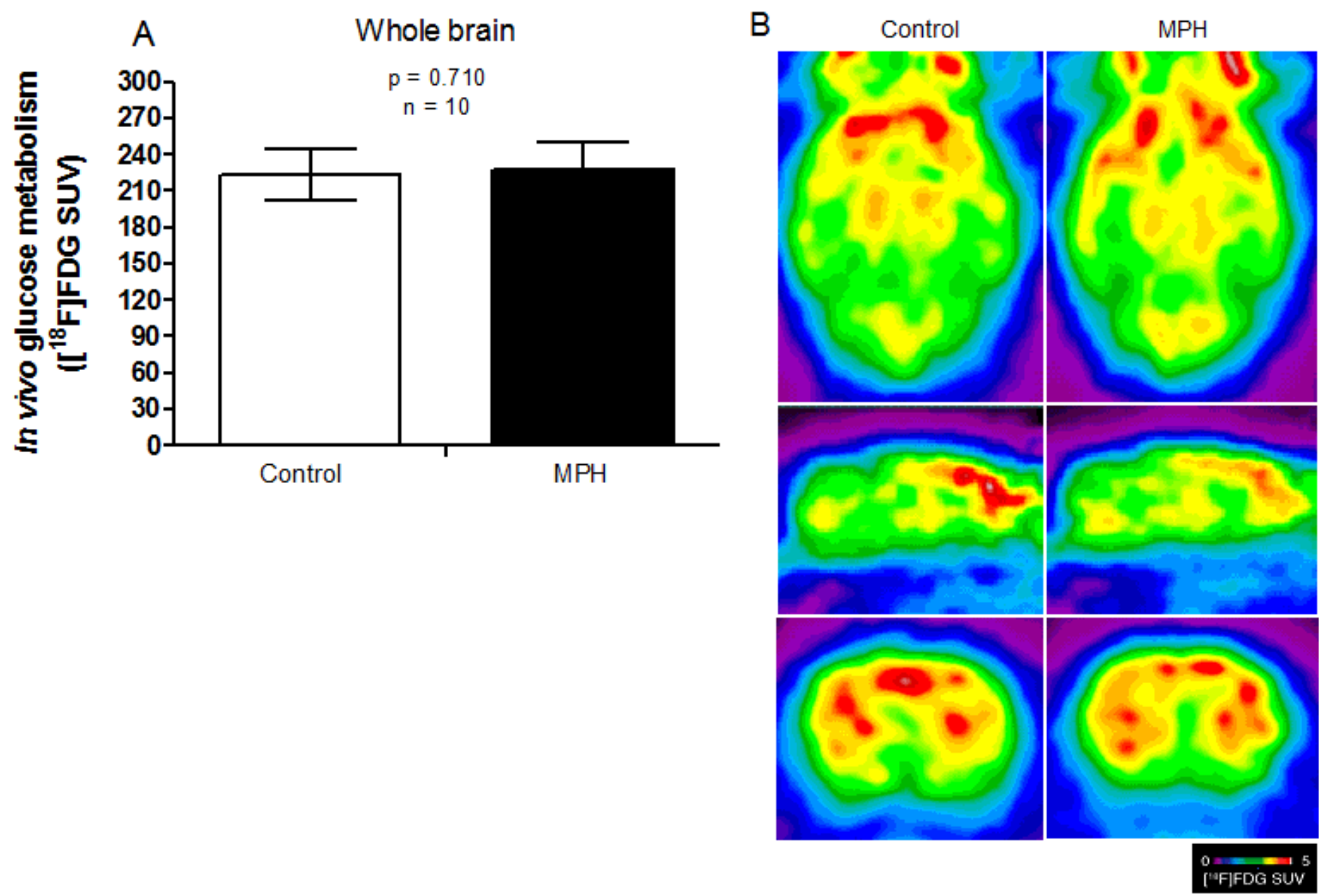
Effects of chronic treatment with MPH on glucose metabolism in the brain. 18F-FDG uptake in the brain (A) and representative microPET images of cerebral 18F-FDG uptake (B). The 18F-FDG uptake was expressed as SUV. Results are expressed as mean \pm standard deviation for 10 animals in each group. Images for control and MPH groups show axial (top), sagittal (middle) and coronal (bottom) sections. SUVr, standardized uptake value ratio; MPH, methylphenidate; 18F-FDG, fluorodeoxyglucose-18; microPET, positron emission microtomography
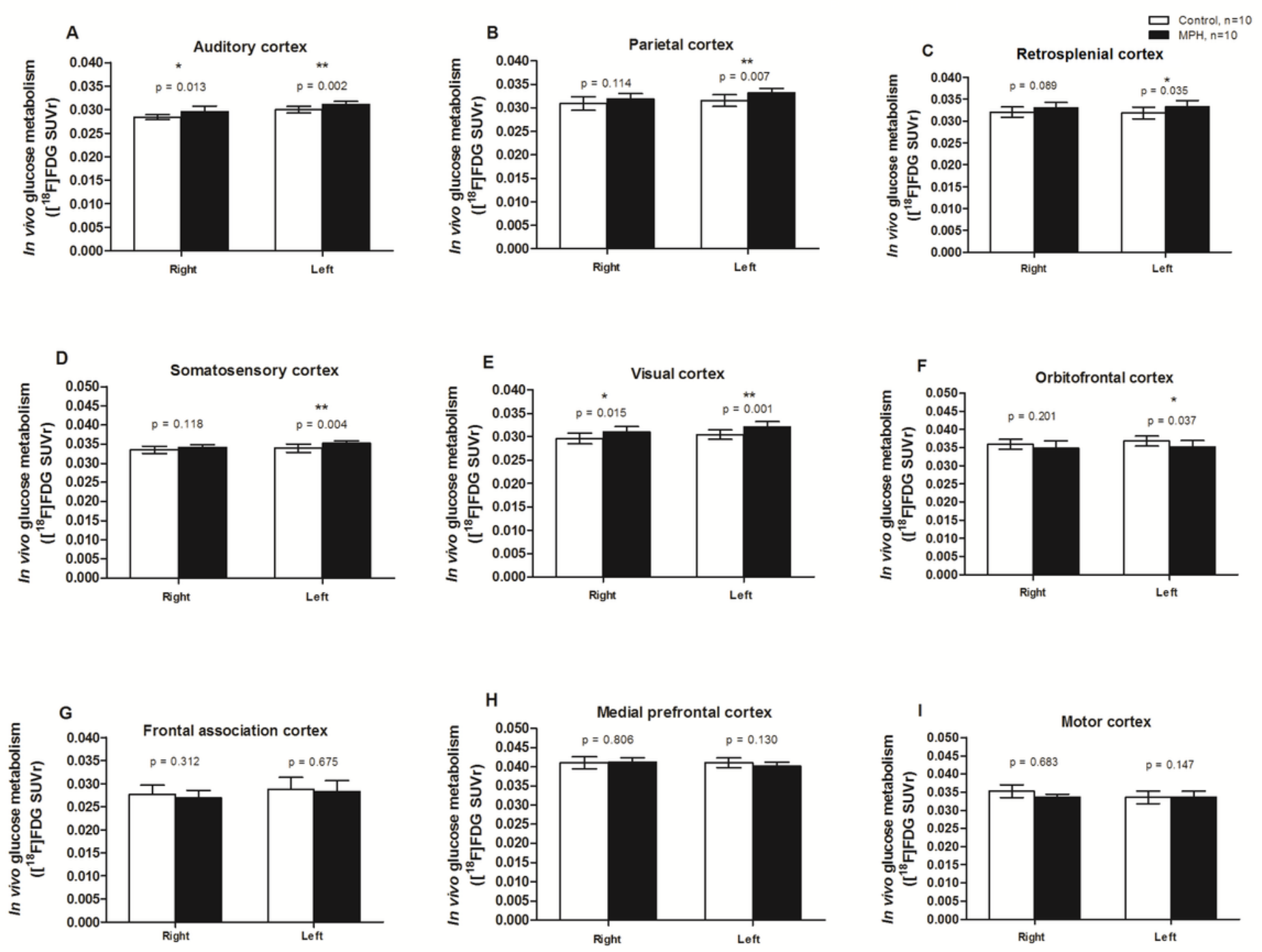

Figure 3

Effects of chronic treatment with MPH on glucose uptake in the auditory cortex (A), parietal cortex (B), restroplenial cortex (C), somatosensory cortex (D), visual cortex $(E)$, orbitofrontal cortex $(F)$, frontal association cortex (G), medial prefrontal cortex (h) and motor cortex (I). Results are expressed as mean \pm standard deviation for 10 animals in each group. Different from control, ${ }^{*} p<0.05$ and ${ }^{* *} p<0.01$ (Student's $\mathrm{t}$ test). SUVr, standardized uptake value ratio; MPH, methylphenidate; 18F-FDG, fluorodeoxyglucose-18; microPET, positron emission microtomography 

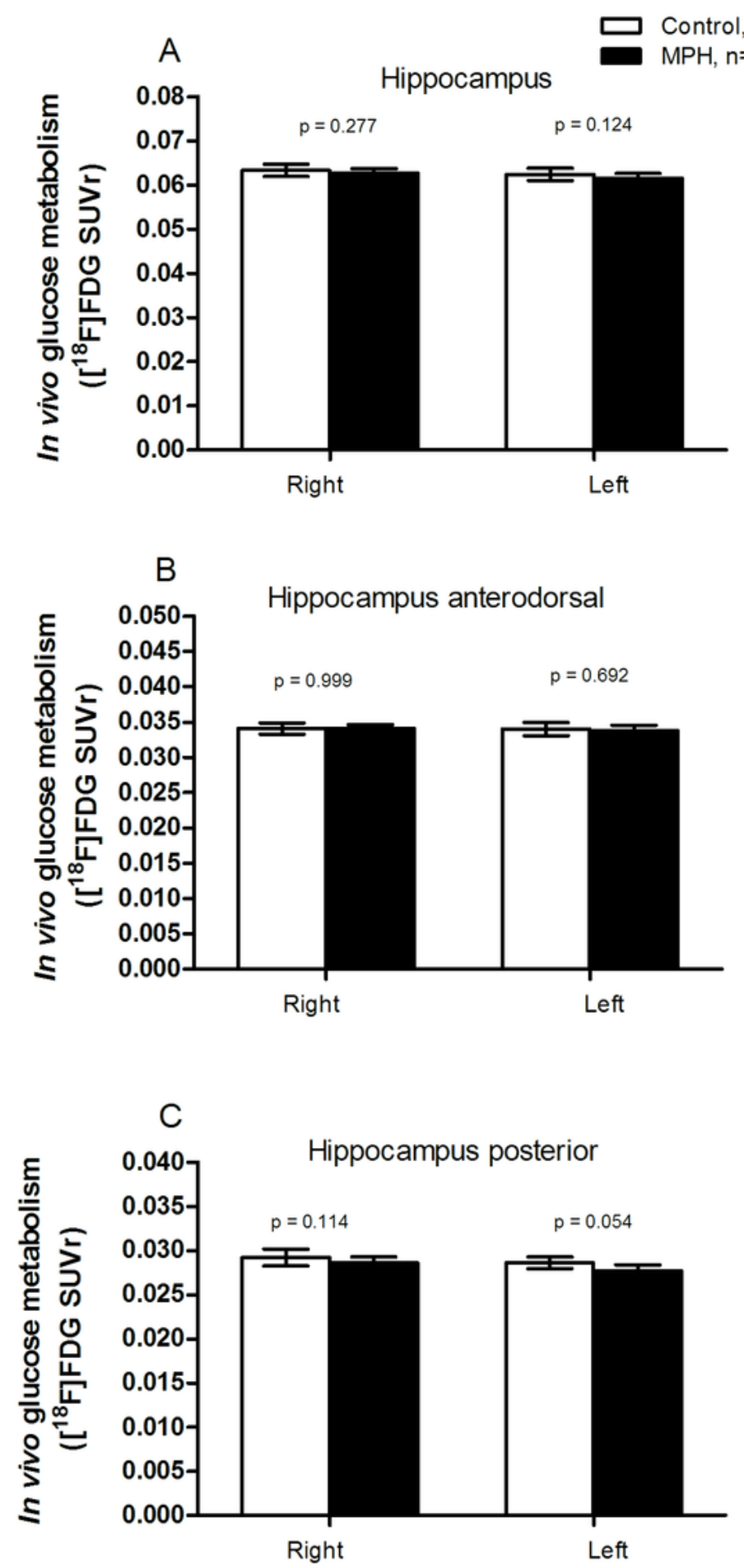

Figure 4

Effects of chronic treatment with MPH on glucose uptake in the hippocampus (A), hippocampus anterodorsal (B) and hippocampus posterior (C). Results are expressed as mean \pm standard deviation for 10 animals in each group. SUVr, standardized uptake value ratio; MPH, methylphenidate; 18F-FDG, fluorodeoxyglucose-18; microPET, positron emission microtomography 


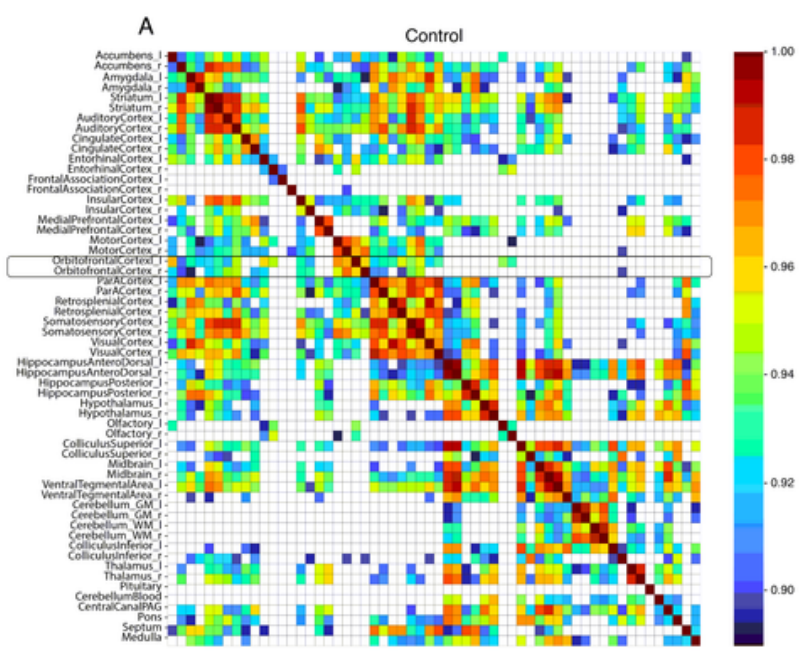

C

Control

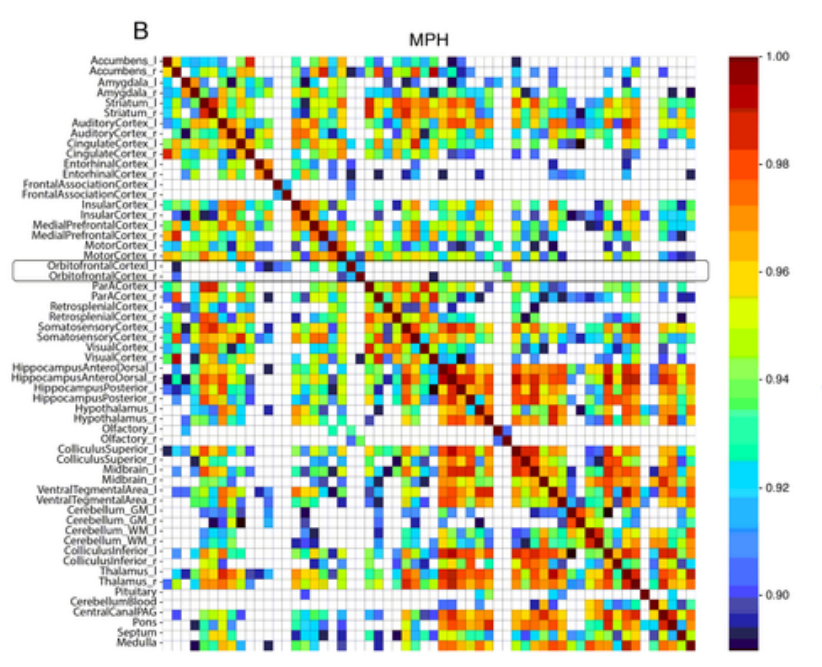

D

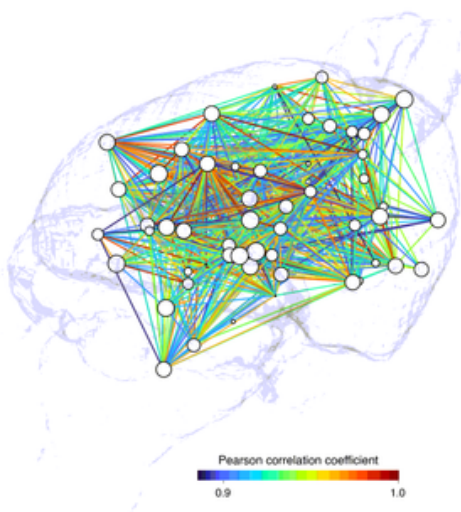

(1)

MPH

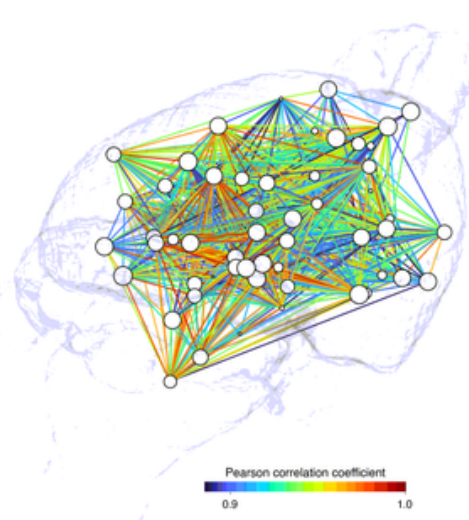

Global graph theoretical measures
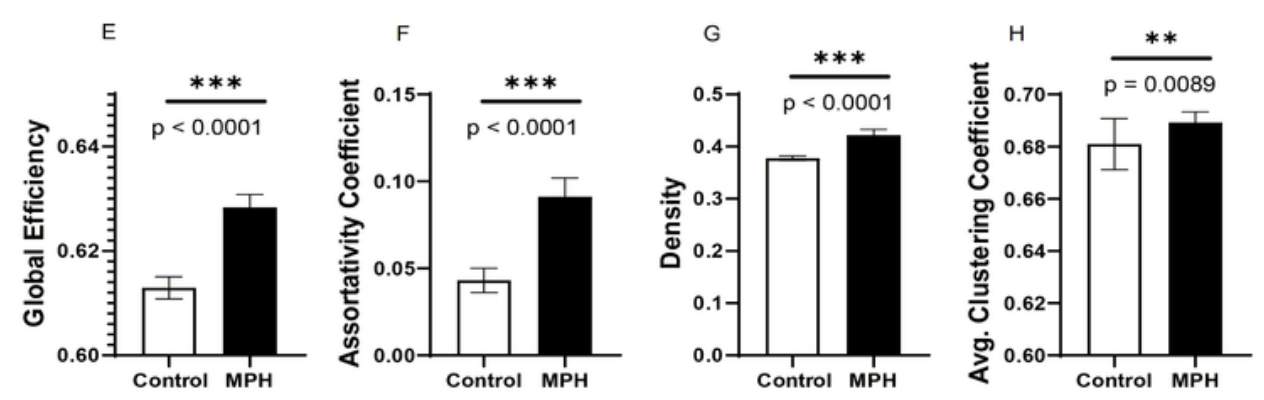

\section{Figure 5}

Metabolic brain networks derived from 18F-FDG SUV. Intersubject Pearson correlation matrices displaying region-to-region associations in control (A) and MPH (B) and 3D brain surfaces displaying metabolic brain networks of Control (C) and MPH (D). Metabolic brain network graph measures of global efficiency $(E)$, assortativity coefficient $(F)$, density $(G)$ and average clustering coefficient $(H)$. Correlation matrices were corrected for multiple comparison using FDR and non-significant correlations are depicted in white. 


\section{Light-dark transition test}
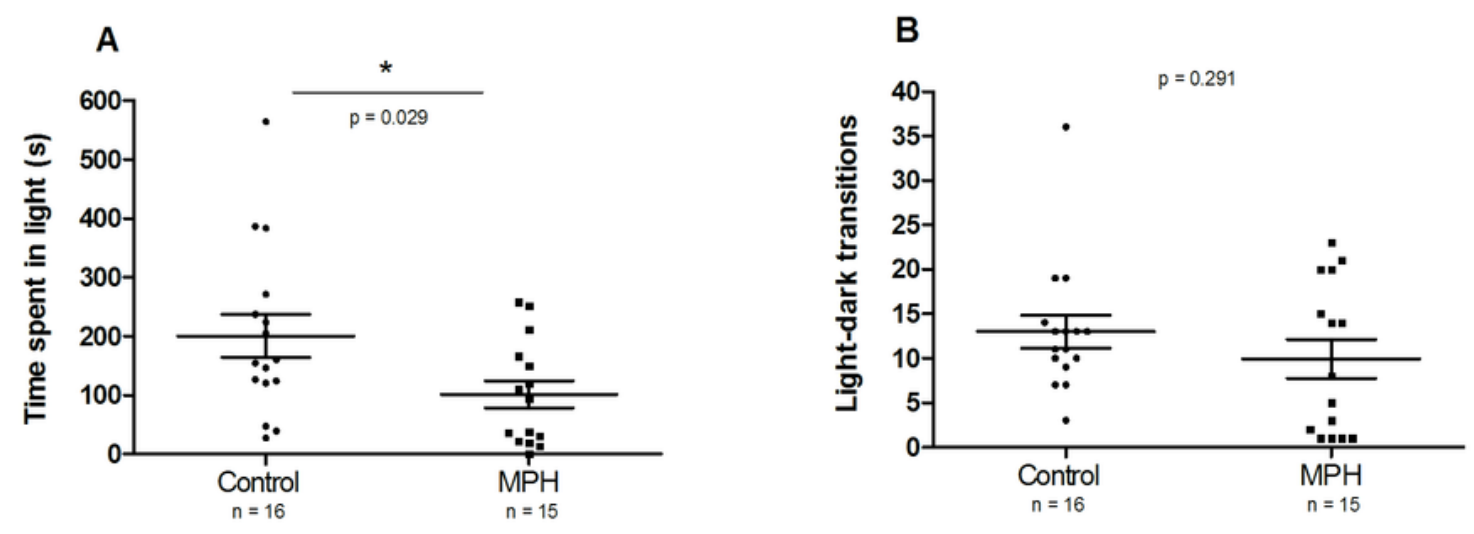

\section{Sucrose preference test}
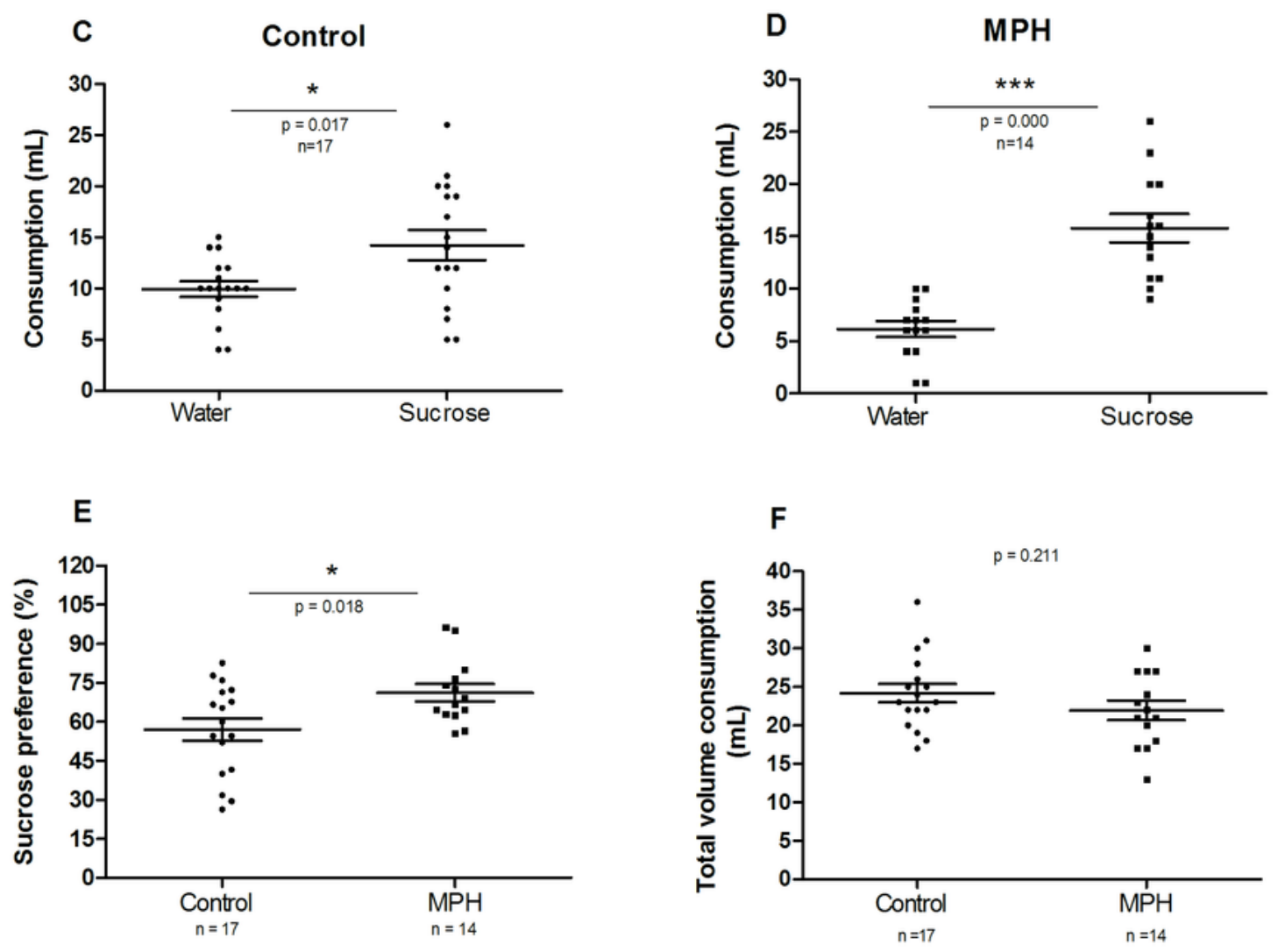

\section{Figure 6}

Effects of chronic treatment with MPH in the light-dark box transition and sucrose preference tests. Time spent in light (A), light-dark transitions (B), water and sucrose consumption in control group (C) and MPH group (D), sucrose preference (E), and total volume consumption (F). Data are expressed as mean \pm standard error mean for 14-17 animals in each group. Different from control, ${ }^{*} p<0.05$ and ${ }^{* *} \mathrm{p}<0.001$ (Student's $t$ test). MPH, methylphenidate 


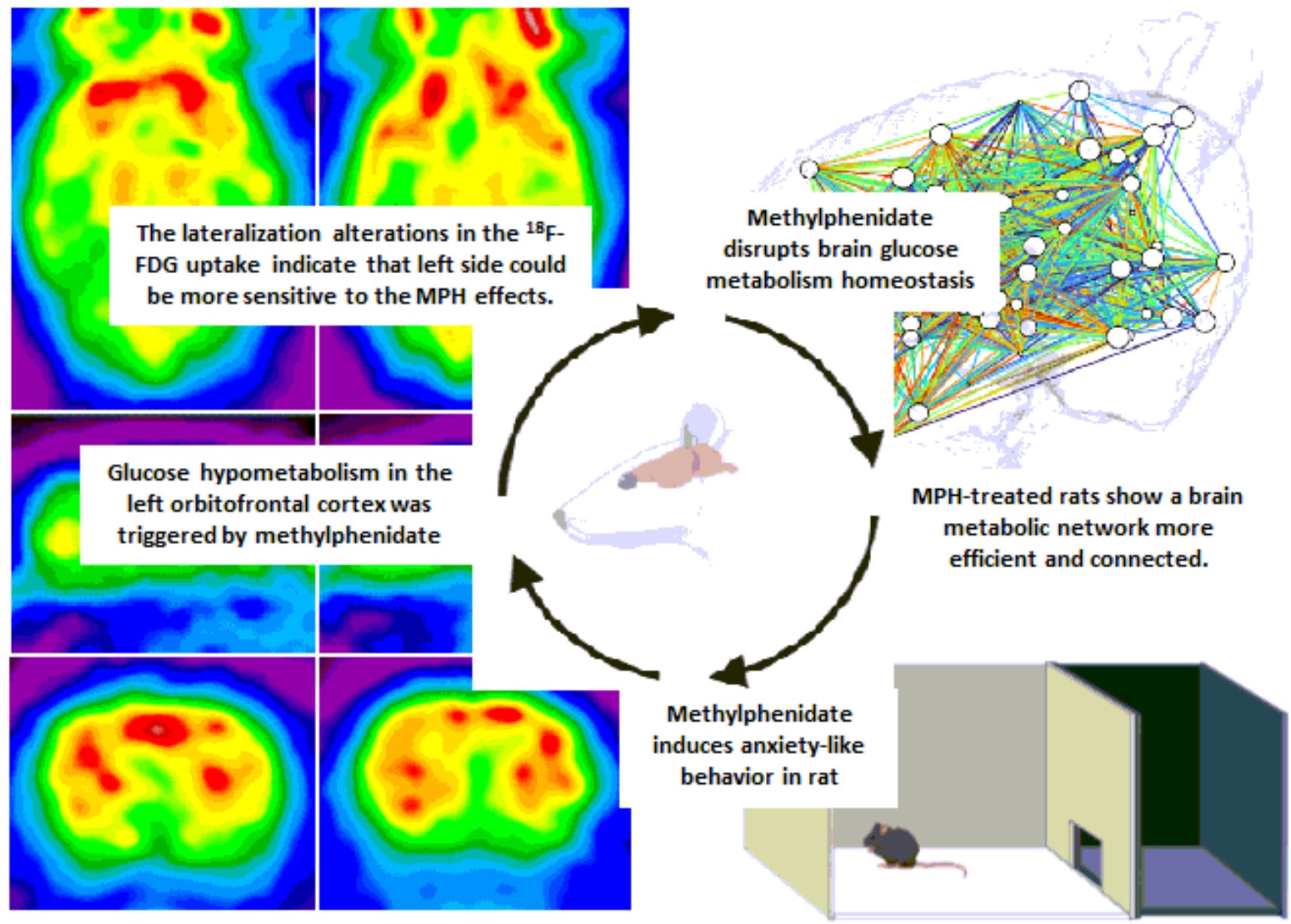

Figure 7

Graphical summary of the processes that were quantified throughout the investigations, highlighting the main effects of chronic early treatment with MPH on crucial parameters for the proper functioning of CNS in rats. Summing up, we showed that MPH treatment evokes different alterations in glucose metabolism and in the metabolic network. Further, there were lateralization alterations in the 18F-FDG uptake in specific brain regions, indicating that left side could be more sensitive to the MPH effects. Also, these findings could be associated, at least in part, with behaviors alterations, highlighting once again the MPH potential to affect the CNS during its development.

\section{Supplementary Files}

This is a list of supplementary files associated with this preprint. Click to download.

- FigureS1.tif

- Figures2.tif

- TableS1.doc 